experiments in which effects had only been investigated for a fow hours and it had been realized that an important factor in the cell viability problem was the ability or otherwise of irradiated cells to develop into colonies. The most recent experiments had therefore been designed to study the development of single cells for 7 days after irradiation with a microbeam of heterochromatic ultraviolet light. At the end of this time, several irradiated cells had formed small colonies which contained a number of morphologically normal cells. A study of the DNA metabolism of individual cells in these colonies at 7 days showed many anomalies, even in the morphologically normal cells.

Forer gave a brief account of the use of polarizing microscopy coupled with ultra-violet microbeam irradia. tion to study the effects on chromosome separation when a small volume of the spindle fibres is irradiated, and Glubrecht presented some results which were obtained when moss cells were irradiated with a monochromatic ultra-violet microbeam. In the latter experiments, cell killing was most efficient when $\mathrm{I}=$ giation at $\lambda=2650 \AA$ was directed at the nucleus but ${ }^{\prime} \lambda=2800 \AA$ was most efficient when directed at the eytoplasm.

The meeting ended with a tour of the new Laboratoire de Pathologie Cellulairo, and the Chairman thanked Prof. Bessis for making all the arrangements for the meoting and thanked the representative of NATO, Ing. Gen. Giboin, for financial support.

P. P. DENDY

${ }^{1}$ Seidel, F., and Buchholtz, C., Naturwissenschaften, 47, 360 (1960).

2 Sced, J., Proc. Roy. Soc., B, 152, 387 (1960).

\title{
IODINE-LABELLED PROTEINS AND HORMONES
}

$\mathrm{E}$ NCOURAGED by the success of a symposium in 1964 on the preparation and biomedical application of labelled molecules Euratom has sponsored another more specialized meeting on problems connected with the preparation and use of labelled proteins. This was held at the University of Pisa in January 1966 and attracted some 150 participants. As might be anticipated from a survey of the literature, nearly all the communications were concerned with proteins labelled with iodine isotopes, the 3 -day conference being broadly equally divided into sessions on hormones and non-hormonal plasma proteins.

Hughes (Boston) reviewed the chemistry of iodination and the particular chemical requirements for satisfactory trace-labelling of proteins. For most purposes the protein should retain its biological activity after labelling. He considered that iodotyrosines might conceivably be used in vivo for protein synthesis but the opportunity seldom presented for this to happen because of the widespread distribution and rapidity of action of tissue deiodinases. Rosa (Saluggia) emphasized the importance of achieving a truly random distribution of isotopic iodine throughout the population of protein molecules and produced further details of the electrolytic method of doing this which he has elaborated in collaboration with Donato and his group at Pisa. It remained for Freeman (London) to discuss biological methods of verifying that the labelled protein is a reliable tracer since it is generally accepted that only in vivo tests are sufficiently sensitive. He mainly favoured measurements of retention in the livers of rats, of catabolic rates in rabbits (if necessary rendered tolerant to human proteins), and of iodide activities in the urine and body water in the first $24 \mathrm{~h}$ in man. These and other speakers emphasized the crucial importance of using only proteins which have been circumspectly handled before labelling, and of taking steps afterwards to minimize self-irradiation damage.

In introducing a session on metabolic studies with labelled plasma proteins MeFarlane (London) recommended that speakers should refer specifically to absolute or fractional rates of turnover as the case might be. Since iodine isotopes are not used for protein synthesis, conclusions about synthesis can only be derived indirectly from slopes of plasma specific activity curves of animals in metabolic equilibrium. These are proportional to fractions of the total body pool synthesized in unit time whereas currently used procedures for measuring catabolic rates give them as fractions of the plasma pool. It was important therefore also to specify the pool. Bianchi (Pisa) and Sorin reviewed the use of jodine-labelled albumin in metabolie studies, Andersen (Copenhagen) did the same for $\gamma$-globulin and Regoeczi (London) for fibrinogen. These were mainly straightforward communications, but controversial questions arose when subsequent speakers discussed mechanisms for regulating plasma protein turnover. Rothschild (New York) reported results of experiments in which low albumin concentrations were produced in rabbits by infusing $\gamma$-globulin or dextran and in which little or no change was observed in the mass of albumin catabolized per day. Fractional synthesis rates in these experiments were unrelated to fractional or absolute catabolic rates, to albumin pool sizes or to concentrations and in fact were sub-normal. This apparent paradox could be resolved by postulating a control mechanism based on the colloid osmotic pressure of hepatic interstitial albumin which is assumed to be increased by injections of $\gamma$-globulin or dextran. Dykes (Birmingham), on the other hand, found greatly reduced absolute catebolic rates in cirrhotic patients with low albumin concentrations both of which were restored to normal by infusions of albumin. He visualized a second-order relationship between albumin concentration and absolute catabolic rate.

Included in a variety of shorter papers were descriptions of the preparation and use of tritium-labelled plasma proteins by Gostonyi et al. (Budapest) and by Gerber et al. (Mol, Belgium). Gordon and Jacques (London) reported on the distribution of iodine-labelled proteins in subcellular particles of the rat liver. Høedt-Rasmussen (Copenhagen) reported on a 10-20 per cent extravaseular catabolism of parenterally administered albumin, and Milhaud (Paris) on the effects of ligaturing the thoracic duct on ${ }^{131} \mathrm{I}$-albumin distribution and metabolism in rats.

Most fittingly, a culminating session to this part of the conference consisted of a round-table discussion of mathematical methods of analysing results. Experts on the panel comprised Donato (Pisa), Matthews (London), Nosslin (Malmö), Segrò (Camerino), and Vitek (Prague). The more recently published methods of Nosslin, which are largely independent of compartmental considerations, received most attention. While Nosslin agreed that his second method, which is based on integrating areas under plasma and total body activity curves, might be less vulnerable to orrors associated with identifying terminal slopes of these curves, he considered it was not altogether free of them, and indeed that the accuracy of all methods was to some extent limited by this factor. The deconvolution method of Vitek and Donato was also the subject of some discussion, as was the use of analogue computers by Segrè.

In the sessions on hormone labelling it was soon apparent that a greater degree of protein modification is permissible and altogether higher specific activities are required. Some seventeen hormones can now be estimated by radioimmunoassay, and Yalow (New York) considered the 
general principles underlying the procedures used, drawing on the extensive experience of the Now York group using insulin, growth hormone, ACTH and parathyroid hormone. Requirements of the labelled hormones were regarded as less stringent than is widely supposed, the essential one being that the plasma hormone and a standard preparation should be equivalent in their capacity to inhibit the reaction between labelled hormone and antiserum. It follows that neither the animal species from which the standard preparation, or the preparation for iodination, is obtained nor, within limits, the degree of damage suffered during iodination is critical. There was general agreement, however, that some purification of the labelled hormone is essential and methods for doing this were described. The possibility that metabolic fragments of endogenous hormones which are immunologically but not hormonally active might be present in plasma was also discussed. The general problem of damage to hormones was included in a round table session organized by Milhaud (Paris).

Some fifteen successful assays using the chloramine $T$ method have been carried out in various laboratories, but Greenwood (London) referred to unsatisfactory experiences with iodine-131 obtained since 1964. Results with the method in the United States had been more consistent than those obtained elsewhere and this seemed to depend mainly on higher specific activities of the available iodine-i31. Michel (Paris), Quabbe (Berlin), Brauman (Brussels) and Franchimont (Liège) had broadly shared Greenwood's experience. The determination of ${ }^{131} \mathrm{I}$ specific activities was outlined by Yalow. In view of the lack of knowledge of iodine and radioiodine chemistry emphasized by Hughes any improvement in the precision of micro-iodine estimations must be welcomed.

The availability of standard preparations of human growth hormone and antisera was discussed by various speakers including Coates (London) and Stewart (Frankfurt). Rosa (Pisa) and Ooms (Brussels) presented short communications on the immunological and biological properties of radioiodinated insulins, while Melani (Frankfurt) reported a procedure for assaying adrenocorticotrophic hormone (ACTH) which depends on the use of an ion exchange resin. The sensitivity of his assay was equivalent to that of the first AC'TH one reported by Berson et al., and this has since been greatly increased. Crosignani and Polvani (Milan) and Freedlender (Boston) reported on assays for human chorionic gonadotrophin and growth hormone respectively which differed in detail from previous assays using the double antibody method. Franchimont (Liège) outlined assays both for human follicle-stimulating hormone and luteinizing tormone, and reported millimicrogram levels during the normal menstrual cycle with two peaks of luteinizing hormone and one of follicle-stimulating hormone. A full report of his procedure is awaited with considerable interest.

In 1963 groups in New York and Washington jointly reported an assay for parathyroid hormone, the procedure having since been improved in sensitivity and applied to humans and animals. Yalow summarized the present position of the New York group and gave unpublished results of human plasma measurements from which it was. evident that clinical application of the method is still hindered by its lack of sensitivity. Potts, on behalf of the Washington group, showed data bearing on the control of animal secretion of the hormone. In the course of this work an identical reaction between crude human parathyroid hormone and purified bovine parathyroid hormone was demonstrated. Availability of purified bovine hormone and antiserum was also discussed.

The elinical and physiological applications of radioimmunoassays were only outlined for insulin by Semols (London) and for glucagon by Weinges (Homburg-Saar) representing Unger's group. Both communications served inter alia to emphasize the usefulness of procedures which can be carried out at rates of up to 200 measurements per week. A discrepancy was noted in the levels of glucagon found in plasma by Samols and Unger, and this may explain the differences in their results after oral administration of glucose.

Abstracts of the papers presented are available ( $J$. Labelled Comp., 1, No. 4, 311) and a full report in book form will appear in due course.

A. S. MCFARLANE F. C. Greenwood

\section{DOMESTIC FOOD CONSUMPTION AND EXPENDITURE}

$D^{o}$ MESTIC Food Consumption and Expenditure, 1963, is the fourteenth annual report produced by the National Food Survey Committee*. The 1962 report reviewed the findings of surveys conducted during the years 1950-60. Over such a period it is easier to observe changing trends in consumption patterns and the quantities of food consumed or purchased than from one year to the next. Nevertheless, interesting facts do emerge from the present report.

Survey methods remained unchanged, but for reasons of economy the sample in the 1963 survey was reduced by 18 per cent as compared with the 1962 sample, the effective size being 7,532 households. There was no change in the average number of persons per household, which again was least in London $(2.95)$ and highest in rural areas (3.41). Because of random sampling, rural areas were over-represented in the 1963 survey, and in order to correct this bias the national averages in this report have been obtained by weighting the separate averages for the different types of urban and rural areas by the estimated population resident in those areas. The composition of the population is interesting. In social class $A$ there were only eight households with four or

- Ministry of Agriculture, Fisheries and Food. Domestic Food Consumption and Expenditure. 1963-Annual Report of the National Food Survey (Yommittee. Pp. $\mathrm{ix}+131$. (London: H.M.S.O., 1965.) 128. 6d. net. more children and only very cautious conclusions can be drawn from this sample. The representation of old-age pensioners, of whom two-thirds were women, further increased. It appears that the highest proportion of elderly men live in the south-west region. The average number of earners per household tended to vary inversely with the income of heads of households including a number of children, and adult earners tended to be fewer in Class $D$ than in any other earning classes because of the smaller average number of adults per household. The highest number of earners was in families containing adolescents.

The exceptional severity of the 1963 winter adversely affected the supply and distribution of certain foods and this in turn affected prices during the first quarter of the year. Over the year, and for the country as a whole, the average total expenditure was $32 s .4 d$. per week, a slight increase over 1962, which can be explained partly by a rise in food prices and partly by an increase in the quantity of food purchases. Expenditure on 'convenience foods' rose to $6 s$. $1 d$. per head per week as compared with $5 s$. $11 d$. in 1962 , but remained at about 19 per cent of the household food budget. Consumption of dairy products and eggs increased, while the consumption of fish fell. Consumption of poultry increased, though at a slower rate than previously, probably at the expense of meat, the 